\title{
ELLIPSOMETRY OF SILVER ELECTRODES IN BASE SOLUTIONS UNDER DIFFERENT POTENTIAL CONTROLLED PERTURBATION CONDITIONS
}

\author{
M. López Teijelo, * J. O. Zerbino, J. R. Vilche and A. J. Arvía \\ Instituto de Investigaciones Fisicoquimicas Teóricas y Aplicadas, INIFTA, Casilla de Correo 16, Sucursal 4. \\ 1900 La Plata, Argentina
}

(Received 18 July 1983; in revised form 19 December 1983)

\begin{abstract}
The ellipsometric and reflectance response at $5461 \mathrm{~A}$ of silver in $0.1 \mathrm{M} \mathrm{NaOH}$ at $25^{\circ} \mathrm{C}$, is studied in the $\mathrm{Ag}(0) / \mathrm{Ag}(\mathrm{I})$ potential range when the electrode has been subjected to different complex potentiodynamic perturbations. The optical response depends remarkably on the potential sweep rate, on the accumulated anodic charge and on the number of potential cycles. The data of the complex anodic film can be interpreted in terms of a single film model in two limiting cases defined in terms of the anodic charge involved as thin and thick films, respectively: (i) for thin anodic films $\left(Q_{\mathrm{a}}<50 \mathrm{mC} \mathrm{cm}^{-2}\right) \bar{n}_{\mathrm{f}}=1.50-0.12 \mathrm{i}$ and (ii) for thick anodie films $\left(Q_{\mathrm{a}}>50 \mathrm{mC} \mathrm{cm}^{-2}\right) \bar{n}_{\mathrm{f}}=1.50-0.22 \mathrm{i}$. Time dependence of the optical parameters of both reformed silver and anodic film are shown. Optical results correlates with electrochemical data recently reported and are discussed in terms of differenl degree of lyydralions for each type of anodic film.
\end{abstract}

\section{INTRODUCTION}

The use of silver oxide electrodes in electrochemical cells estimated the study of the anodic oxidation of silver in base solutions [1-22]. For this purpose ellipsometry is a valuable technique for in situ measurements of the thickness and optical characteristics of the anodic film, as it was demonstrated in the study of the anodic oxidation of silver in base under galvanostatic conditions [23]. The formation of the anodic layer of silver oxide is a complex electrochemical process which involves simultaneous charge transfer and chemical rearrangements of the film constituents[21], and, under certain conditions, the chemical dissolution of the film as anionic silver[19].

Results obtained under galvanostatic conditions [23] were explained with a complex multilayer structure of the metal/solution interphase resulting after anodization. However, recently reported kinetic data on silver electrooxidation to silver(I) oxide under potential controlled conditions [22] showed a dependence on the charge involved in anodic film formation and the overall process was interpreted in terms of two limiting sandwich-like structures of the anodic film. On the other hand, the electroreduction of the anodic layer yielded an electrodeposited silver surface (reformed silver) whose reactivity was different than that of the initial polished silver[24].

The present paper deals with the changes in the ellipsometric parameters occurring during the anodic formation of silver(I) oxide films on silver in base electrolyte and the correlation of these results with those derived from the electrochemical measurements[22]. The reaction model formerly advanced, where a silver(I) oxide hydration change in depth was

* Present address: Departamento de Fisicoquímica, Facultad de Ciencias Químicas, Universidad Nacional de Córdoba, Suc. 16, Casilla de Correo 61, 5016 Córdoba, Argentina. assumed, is valid for the optical data obtained for anodic layers electroformed under potential controlled conditions.

\section{EXPERIMENTAL}

Working electrodes consisting of circular plane area $\left(0.385 \mathrm{~cm}^{2}\right)$ of polycrystalline silver $99.9999 \%$ purity (Johnson, Matthey Chemicals) mounted in a Teflon holder were used. They were gradually polished starting with grade 600 emery paper and finishing with 0.05 micron alumina on a polishing cloth (Microcloth). Finally, the electrodes were repeatedly cleaned with distilled water.

The electrolyte solution, $0.1 \mathrm{M} \mathrm{NaOH}$, was prepared from Merck analytical reagent grade $\mathrm{NaOH}$ and triply-distilled water and it was kept continuously under a nitrogen atmosphere.

A three-compartment glass made electrolysis cell was employed. The silver working electrode was horizontally placed in a cell compartment provided with two plane glass windows adequated for optical measurements. Its potential was measured against a hydrogen electrode at the electrolyte concentration, although potentials in the text are given in the nhe scale. The counterelectrode was a spiral shape platinum wire.

The electrolysis cell was mounted in a Rudolph Ressearch type 437-02/200 B manual ellipsometer (maximum resolution $0.01^{\circ}$ ) provided with a $150 \mathrm{~W}$ tungsten lamp with filter ( $5461 \AA$ ) and a RCA $1 P 21$ photomultiplier. The incidence light beam angle was fixed at $71^{\circ}$ and that of the compensator at $135^{\circ}$. Runs were made at $25^{\circ} \mathrm{C}$.

Initially the ellipsometric data of the polished silver electrode both under open circuit conditions and at the cathodic switching potential $\left(E_{\mathrm{s}, \mathrm{c}}=-0.15 \mathrm{~V}\right)$ were measured. The corresponding readings at the polarizer $\left(\Gamma_{0}\right)$ and at the analyzer $\left(A_{0}\right)$ were in both cases 
coincident. The values $P_{\mathrm{o}}$ and $A_{\mathrm{o}}$ of the initial polished silver yielded the corresponding refractive index $\left(n_{\mathrm{s}}\right)$ and absorption coefficient $\left(k_{\mathrm{s}}\right)$ values of the substrate. The complex refractive index $\left(\bar{n}_{\mathrm{s}}\right)$ is defined as $n_{\mathrm{s}}-i k_{\mathrm{s}}$. Both $n_{\mathrm{s}}$ and $k_{\mathrm{s}}$ values derived for polished silver coincide with those earlier reported by different authors [23, 25].

The ellipsometric readings ( $P$ and $A$ ) of the electrode covered with the anodic film were made in different ways. In one case, (procedure A) the anodic film corresponding to the charge $Q_{\mathrm{a}}$ was firstly formed under a linear potential sweep (LPS) from $E_{\mathrm{s}, \mathrm{e}}=-0.15 \mathrm{~V}$ up to $E_{\mathrm{s}, \mathrm{a}}\left(0.35 \mathrm{~V} \leqslant E_{\mathrm{s}, \mathrm{a}} \leqslant 0.70 \mathrm{~V}\right)$ at a potential sweep rate $v\left(2 \times 10^{-4} \mathrm{Vs}^{-1} \leqslant v\right.$ $\leqslant 0.1 \mathrm{~V} \mathrm{~s}^{-1}$ ). Immediately afterwards the anodic current at the potential $E_{\mathrm{s}, \mathrm{a}}$ was switched off and the values of $P$ and $A$ were read at different preset times counted from the current interruption. Later, the anodic film growth under anodic potential sweep was continued from the open circuit pntential to another $E_{s, \mathrm{a}}$ value. Then, the anodic current was again interrupted and the value of $P$ and $A$ were read at another open circuit condition. This stepwise procedure to evaluate $P$ and $A$ under open circuit conditions was repeated so that $E_{\mathrm{s}, \mathrm{a}}$ covered the whole potential range related to the silver(I) oxide electroformation. Hence, the gradual increase in $Q_{\mathrm{a}}$ implied anodic films of increasing average thicknesses.

The values of $P$ and $A$ were also read without interrupting the anodic current (procedure B), that is during the positive potential scan. For this purpose runs were made at $v=2 \times 10^{-4} \mathrm{Vs}^{-1}$ and measurements were performed during the first potential sweep starting from the polished silver surface as well as during the successive repetitive triangular potential sweeps starting from $E_{\mathrm{s}, \mathrm{e}}$ with the reformed silver surface.

The electrode reflectance during single and repetitive triangular potential sweeps (STPS and RTPS) was also determined. In this case, the relative reflectance change per cent $\left(\Delta R / R_{\mathrm{o}}\right)$ as a function of potential was evaluated in the different potential sweeps. Voltammetric potential/apparent current density $(E / i)$ profiles were also made to correlate the optical data with the electrochemical response of the system.

\section{RESULTS}

The RTPS voltammograms run at $0.02 \mathrm{~V} \mathrm{~s}^{-1}$ between $E_{\text {s.c }}=-0.15 \mathrm{~V}$ and $E_{\text {s.a }}=0.75 \mathrm{~V}$ (Fig. 1) show in the positive potential scan anodic current peaks I, II and III, at $0.37,0.46$, and $0.57 \mathrm{~V}$, respectively, which are related to the formation of various silver(I) oxygen containing species. The reverse scan exhibits the corresponding complex electroreduction current peak. In this case, the electrooxidation $\left(Q_{\mathrm{a}}\right)$ and the electroreduction $\left(Q_{\mathrm{c}}\right)$ charges are equal. This suggests that after the electroreduction scan apparently no oxide remains at $-0.15 \mathrm{~V}$ on the silver electrode surface and in this case any dissolution of silver in $0.1 \mathrm{M} \mathrm{NaOH}$ as an anionic species is, in principle, negligible.

The accumulation of anodic charge and the cathodic $E / i$ profile related to the total electroreduction of the oxide comprising different $Q_{\mathbf{a}}$ values, which was formed by stepwise increasing $E_{\mathrm{s}, \mathrm{a}}$ including in each

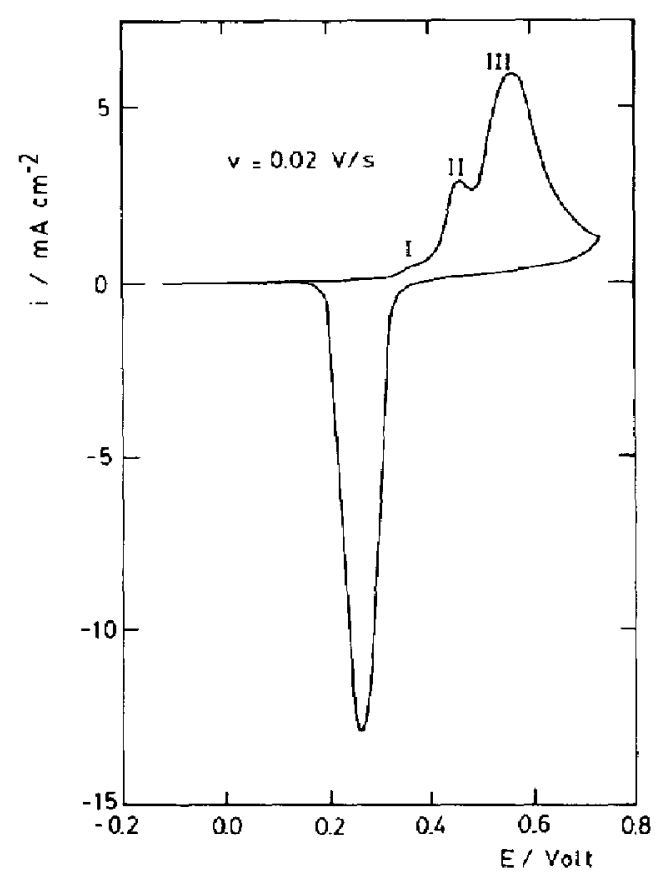

Fig. 1. Stabilized potentiodynamic $E / i$ profile (RTPS) for a silver electrode in $0.1 \mathrm{M} \mathrm{NaOH}, 25^{\circ} \mathrm{C}$.

step an open circuit period, [Fig. 2(a) and (b)] depend considerably on $v$ (Fig. 3). For a constant $E_{\mathrm{s}, \mathrm{a}}, Q_{\mathrm{a}}$ and, consequently, the average thickness of the anodic layer, decreases as $v$ increases. The $Q_{\mathrm{a}} / Q_{\mathrm{c}}$ ratio resulting from Fig. 2 is slightly greater than one. This result suggests that during the interruption of the anodic sweep, there is a partial dissolution of the anodic film under open circuit conditions which depends on $E_{\mathrm{s}, \mathrm{a}}$. However, a partial change in the oxidation state of silver and disproportionation reactions in the anodic film, cannot be immediately discarded as possible contributions to the increase of the $Q_{a} / Q_{c}$ ratio above one.

In the range of $v$ covered by the present runs the values of $P$ and $A$ measured through procedure $A$, depend on $Q_{3}$ [Fig. 4(a) and (b)]. Initially for $Q_{\mathrm{a}}<10 \mathrm{mCcm}^{-2}$, both $P$ and $A$ decrease as $Q_{\mathrm{a}}$ increases, although their rate of change is small as compared to the experimental errors. Otherwise, in the $10 \mathrm{mC} \mathrm{cm}^{-2}<Q_{\mathrm{a}}<40 \mathrm{mC} \mathrm{cm}^{-2}$ range, both $P$ and $A$ increase with $Q_{\mathrm{a}}$, but when $Q_{\mathrm{a}}>40 \mathrm{mC} \mathrm{cm}^{-2}$, the rest of the $P$ vs $A$ plot is considerably influenced by the value of $v$. Thus, for $25 \mathrm{mC} \mathrm{cm}^{-2}<Q_{\mathrm{a}}$ $<50 \mathrm{mC} \mathrm{cm}^{-2}$, at $0.02 \mathrm{~V} \mathrm{~s}^{-1}$ and $0.1 \mathrm{~V} \mathrm{~s}^{-1}$, an ascending anticlockwise loop is observed in the $P$ vs $A$ plot, while a reverse loop appears at $10^{-3} \mathrm{~V} \mathrm{~s}^{-1}$. Therefore, one concludes that the optical properties of the anodic film depend remarkably on the history of the elcctroformation process.

Each successive point in the $P$ vs $A$ diagram derived from procedure $A$ implies an accumulation of charge. On the other hand, as the stepwise readings of $P$ and $A$ imply an interruption of the electroformation process during a certain time ( $\tau$ ), the readings were made at $\tau=$ constant to attain comparable conditions in relation to ageing and restructuring processes in the 


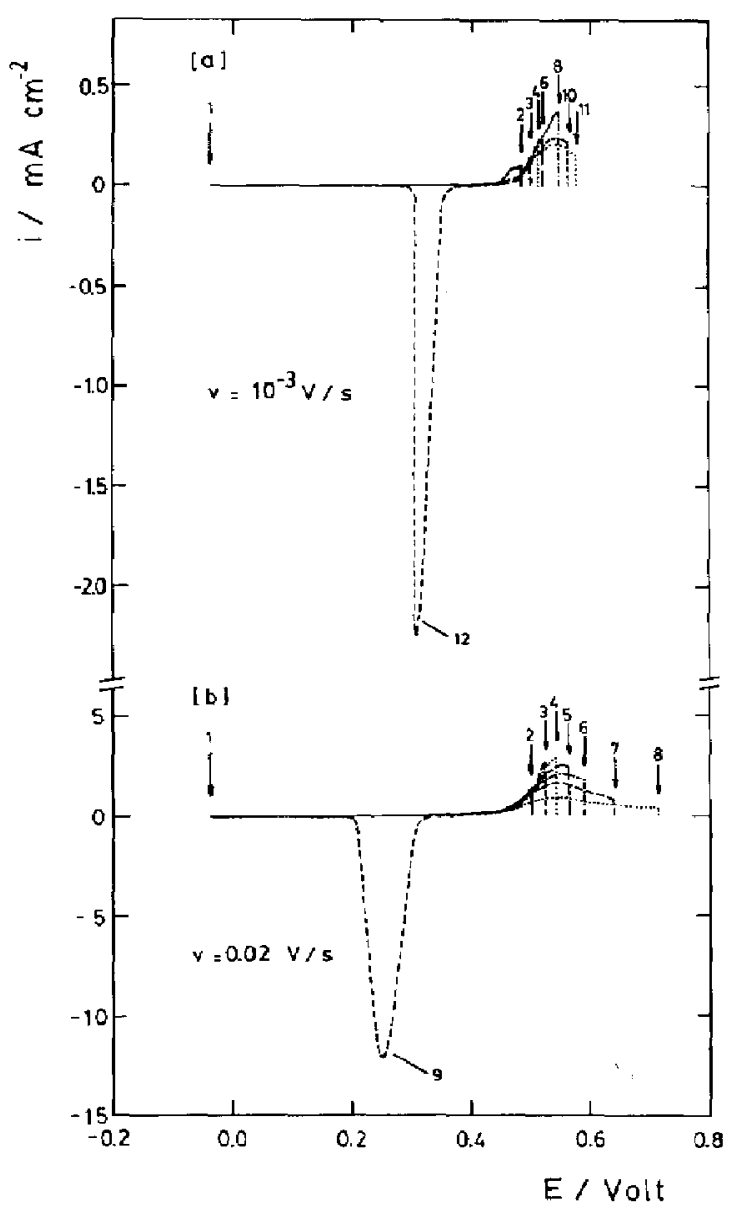

Fig. 2. (a) Potentiodynamic $E / i$ profiles at different $v$ with anodic current interruptions for the time required for the ellipsometric readings and later stepwise increase of $E_{s, a}$. The corresponding perturbation program is the same shown in Fig. 4. (b) Details of the potentiodynamic $E / i$ profiles depicted in (a).

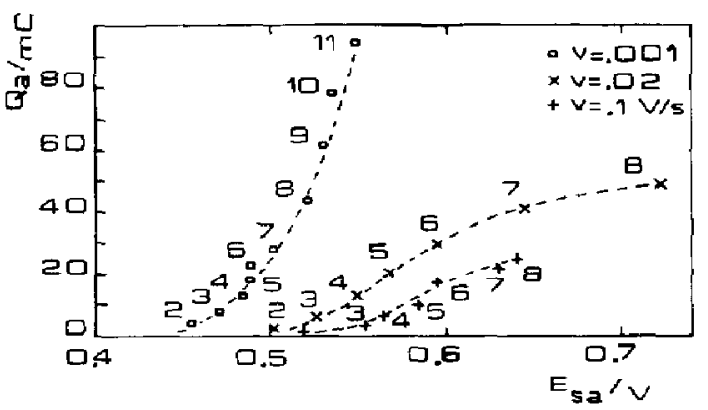

Fig. 3. Dependence of $Q_{\mathrm{a}}$ on $E_{\mathrm{sa}}$ at different $v$. Data derived from Fig. 2. The numbers identify the $E_{\mathrm{s}, \mathrm{a}}$ values in Fig. 2 and are related to the corresponding ellipsometric measurernents in Fig. 4.

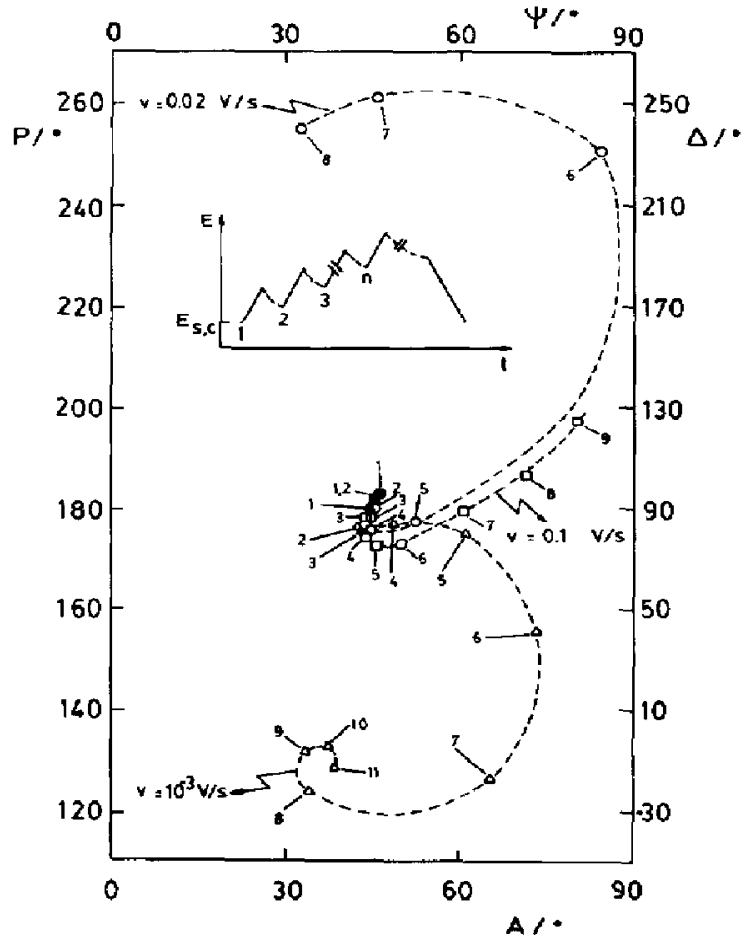

Fig. 4. (a) $P$ vs $A$ ( $\Delta v s \Psi$ ) plots resulting for different anodic film electroformation charges obtained at three different potential sweep rates. (b) Details of the $\Delta$ us $\Psi^{\prime}$ plots depicted in (a).

anodic film. Certainly, for thick films $\left(Q_{\mathrm{a}}\right.$ $>100 \mathrm{mC} \mathrm{cm}^{-2}$ ), the sensitivity in the readings of $P$ and $A$ is poor, as the reflectivity of the anodic film is very low. Consequently, data of the final portion of the loop which moves clockwise as $Q_{\mathrm{a}}$ increases should be taken as rather uncertain.

The characteristics of the $P$ vs $A$ plots resulting from the application of procedure $B$ (Fig. 5) at $2 \times 10^{-4} \mathrm{Vs}^{-1}$ also exhibit a loop which moves clockwise as $Q_{\mathrm{a}}$ increases, similar to that described in Fig. 4 for low values of $v$.

The $P$ vs $A$ plots obtained either from procedure $A$ or B depend whether the first potential sweep or the following ones are considered. Thus, for procedure A for the first positive potential scan at $0.02 \mathrm{~V} \mathrm{~s}^{-1}$ (Fig. 6) the loop in the $P$ vs $A$ plot moves anticlock wise as $Q_{a}$ increases, while the reverse occurs for the second and successive positive potential scans. For the latter, the magnitude of the loop decreases during the successive cycles and the $P$ vs $A$ plot becomes qualitatively similar to that observed already for the first positive potential scan at $10^{-3} \mathrm{~V} \mathrm{~s}^{-1}$. This difference is due, in part, to the shift of $P_{\mathrm{o}}$ and $A_{\mathrm{o}}$ values from those of polished silver to that of reformed silver as described further on.

\section{Time-dependence of the optical constants}

The optical constants of polished polycrystalline silver found in this work coincide with those measured by other authors $[23,25]$, although both the optical constants of the substrate and those of the anodic film 


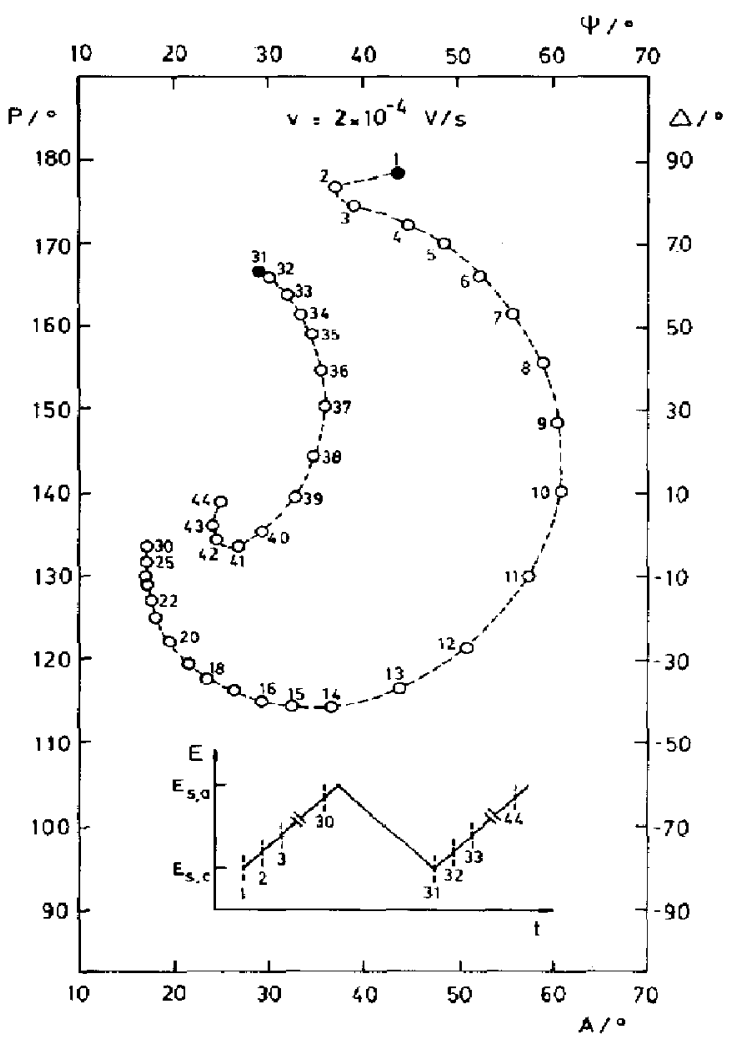

Fig. 5. $P$ vs $A(\Delta$ vs $\Psi$ ) plots for anodic films produced in an accumulative way without interrupting the positive potential sweep. (1) Corresponds to the initial polished silver. Data (2)-(30) were obtained during the 1st positive potential sweep. (31) Indicates the optical parameters of the reformed silver. Data (32)-(44) were obtained during the 2 nd positive potential sweep.

are time dependent. This dependence becomes more remarkable when $Q_{\mathrm{a}}$ is in the order of $10 \mathrm{mC} \mathrm{cm}^{-2}$ or smaller. In all these runs the $P$ and $A$ values obtained at $-0.15 \mathrm{~V}$ after electroreducing the anodic film yielding a reformed silver surface are lower than those corresponding to polished silver $\left(P_{\mathrm{o}}\right.$ and $\left.A_{\mathrm{o}}\right)$. This remarkable difference can be depicted on the basis of an apparent refractive index $\left(n_{\mathrm{ap}}\right)$ and absorption coefficient $\left(k_{\mathrm{ap}}\right)$ of silver. The apparent optical constants of reformed silver depend principally on the quantity of anodic film electroformed during the positive potential going scan (Fig. 7). These dependences are qualitatively similar to those expected from the influence of metal roughness on the optical constants derived from ellipsometry[25]. This explains the different behaviour of the initial portions of the $P$ us $A$ plots during the second and third potential sweeps as compared to the first one (Figs 4 and 5).

Figure 8 depicts the changes of the optical parameters of both the anodic film and the substrate, resulting from the application of procedure $B$. In this case, the film which was formed under preset conditions $\quad\left(v=0.02 \mathrm{~V} \mathrm{~s}^{-1}, \quad E_{\mathrm{s}, \mathrm{c}}=-0.15 \mathrm{~V}, \quad E_{\mathrm{s}, \mathrm{a}}\right.$ $=0.50 \mathrm{~V}$ ), exhibits during the time the electrical circuit is open an increase of $P$, while $A$ remains practically

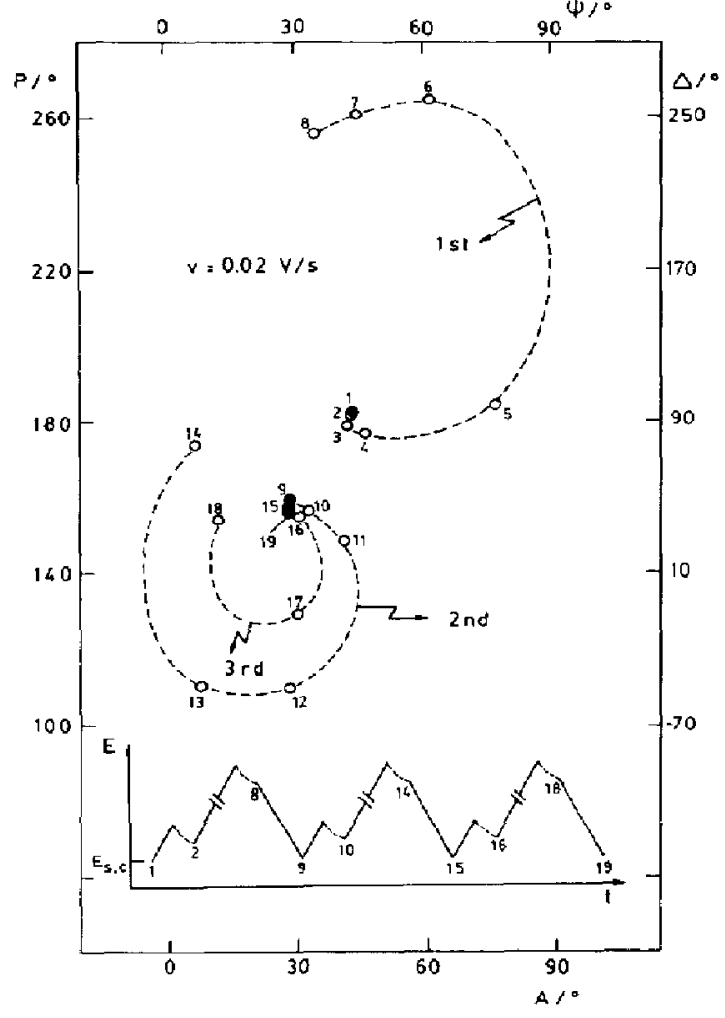

Fig. 6. $P \cup x A(\Delta v s \Psi)$ plots for anodic films electroformed at $0.02 \mathrm{Vs}^{-1}$ during the $1 \mathrm{st}, 2$ nd and 3 rd positive potential scans. The black points correspond to initial polished silver

(1) and to the reformed silver surface $(9,15$ and 19).

constant. Otherwise, the values of $P_{\mathrm{o}}$ and $A_{\mathrm{o}}$ for reformed silver decrease during the successive potential cycling. These results indicate that the ellipsometric parameters plotted in Figs 4 and 7, are to some extent influenced by the time dependence of the optical properties, both of silver and of the anodic film. This influence is likely to be a maximum in the early stages of the anodic film growth and can, in principle, be neglected when $Q_{\mathrm{a}}$ exceeds $10-20 \mathrm{mCcm}^{-2}$ for runs made at $0.02 \mathrm{Vs}^{-1}$.

\section{Reflectivity measurements}

The reflectivity measurements were made during the potential sweep at $0.02 \mathrm{~V} \mathrm{~s}^{-1}$ between $E_{\mathrm{s}, \mathrm{c}}=-0.15 \mathrm{~V}$ and $E_{\mathrm{s}, \mathrm{a}}=0.75 \mathrm{~V}$ (Fig. 9). During the first positive potential scan the reflectivity decreases just when the potential threshold of the anodic reaction is reached. Then, as the potential increases the reflectivity decreases more rapidly to furnish an inflexion point when the potential of the ascending branch of peak III is reached. When the applied potential exceeds that of peak III, the reflectivity decreases more slowly. Finally, another remarkable decrease in reflectivity appears when the potential scan covers the potential range of 


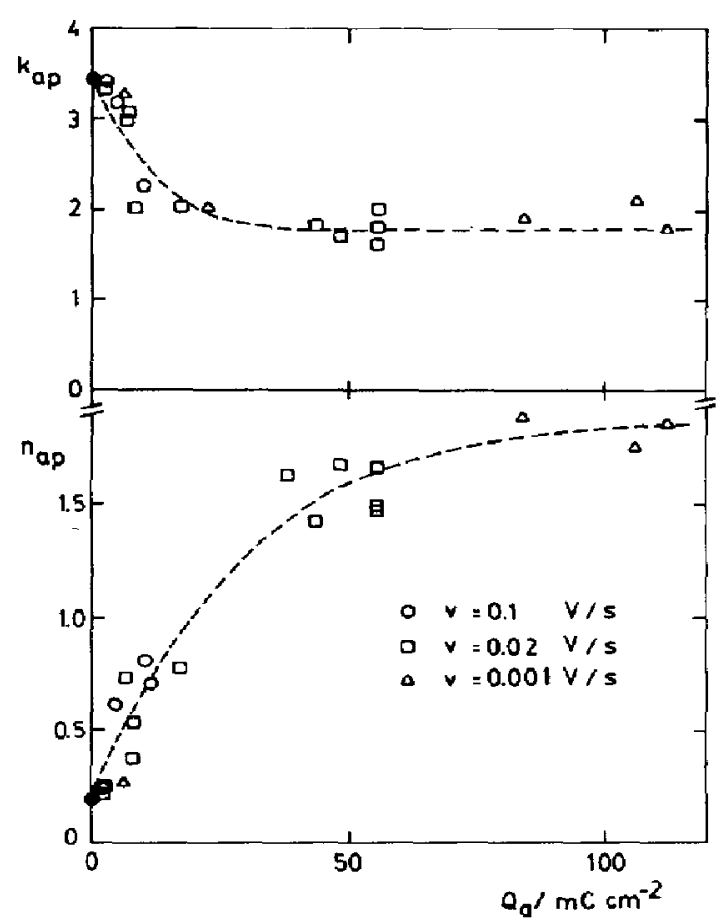

Fig. 7. Dependence of the apparent optical constants of silver on the anodic film electroformation charge at different values of $v$.

the increasing branch of the electroreduction current peak.

The reflectivity of the reformed silver surface resulting after the first traingular potential sweep is much lower than that of the initial polished surface. The reflectivity change observed during the second potential scan is very different of that described for the first potential scan, as the reflectivity increases during the anodization process, reaches a maximum at about $0.65 \mathrm{~V}$, then attains a constant value over a wide potential range and finally, decreases again in the potential range of the electroreduction current peak. In this case, the reflectivity goes through a minimum and finally reaches the initial reflectivity value.

When the electrode is potential cycled during $30 \mathrm{~min}$, relatively small reffectivity changes along the potential range of the anodic process are noticed, but when the potential of peak III is reached it exhibits a considerable decrease in the $0.6-0.75 \mathrm{~V}$ range. The reflectivity value decreases slightly during the negative potential scan until the potential region of electroreduction peak is attained. At this stage the reflectivity increases within a small potential range to approach the initial value. In this case during the repetitive potential cycling the reflectivity at the initiation of each potential cycle decreases slightly.

These results demonstrate that remarkable structural modifications of the electrochemical interface takes place during the course of the triangular potential cycling in the potential region where thermodynamics predicts the formation of the silver(I) oxide anodic layer, under any preset conditions.

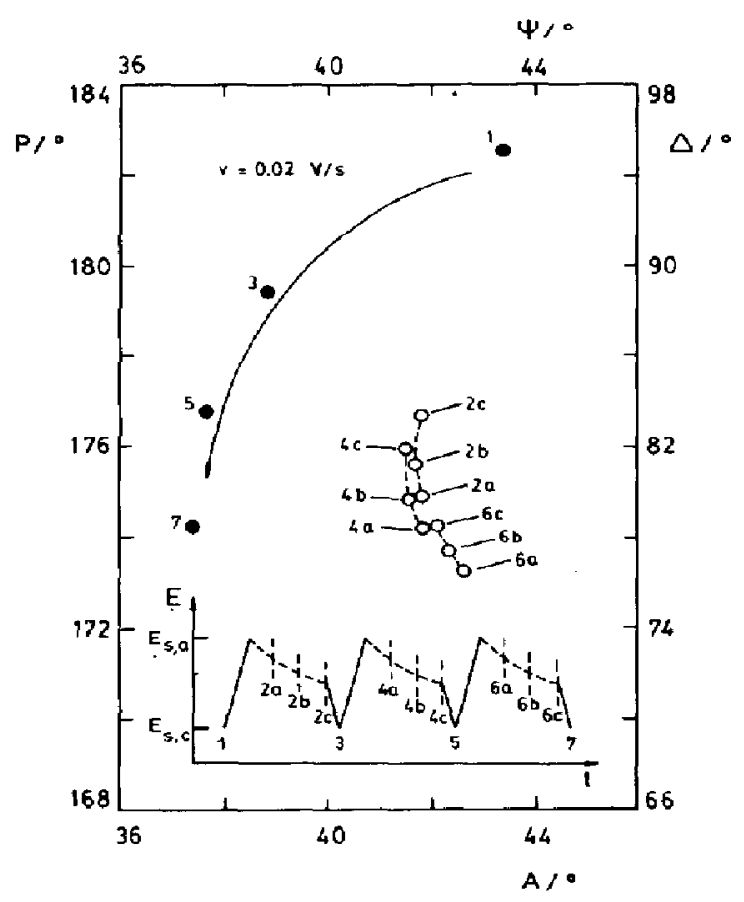

Fig. 8. $P$ us $A$ ( $\Delta$ vs $\Psi$ ) plots for anodic films under open circuit conditions: (2), (4) and (6) correspond to readings made under open circuit after the 1 st, 2 nd and 3 rd positive potential scans, respectively; (a), (b) and (c) correspond to readings made 5,10 and 15 min respectively, atter the current switch off. (1) Corresponds to the initial polished silver, (3), (5) and (T) indicate the optical parameters of the reformed silver resulting after the successive electroreduction sweeps.

\section{DISCUSSION}

The ellipsometric and reflectance data corresponding to anodization of silver in base to silver oxide in the $\mathrm{Ag}(0) / \mathrm{Ag}(\mathbf{I})$ potential range at $5461 \AA$, show various distinguishable behaviours. Thus, the comparison of the ellipsometric results at the very initial stages of the anodic reaction during the first positive potential scan, shows, in this case, a minor influence of the potential perturbation conditions. Then, the corresponding changes of the optical properties of the electrochemical system during the formation of the first layers of anodic product are relatively small. Conversely, the growth of the anodic film depends remarkably on the reaction conditions and on the charge accumulated during the process.

Independently of time effects, the optical data related to the anodic film growth can be qualitatively interpreted in terms of a model consisting of the juxtaposition of two layers (layer I and layer II) each one with a different degree of hydration. The optical constants of these layers depend on the potential sweep rate, the duration of the anodization process and the number of potential cycles. This applies to anodic films produced either by procedure A or B. It is interesting to emphasize that the dual behaviour of silver anodization in base, as derived from ellipsometric data at $5461 \AA$, correlates with the dual kinetic behaviour 


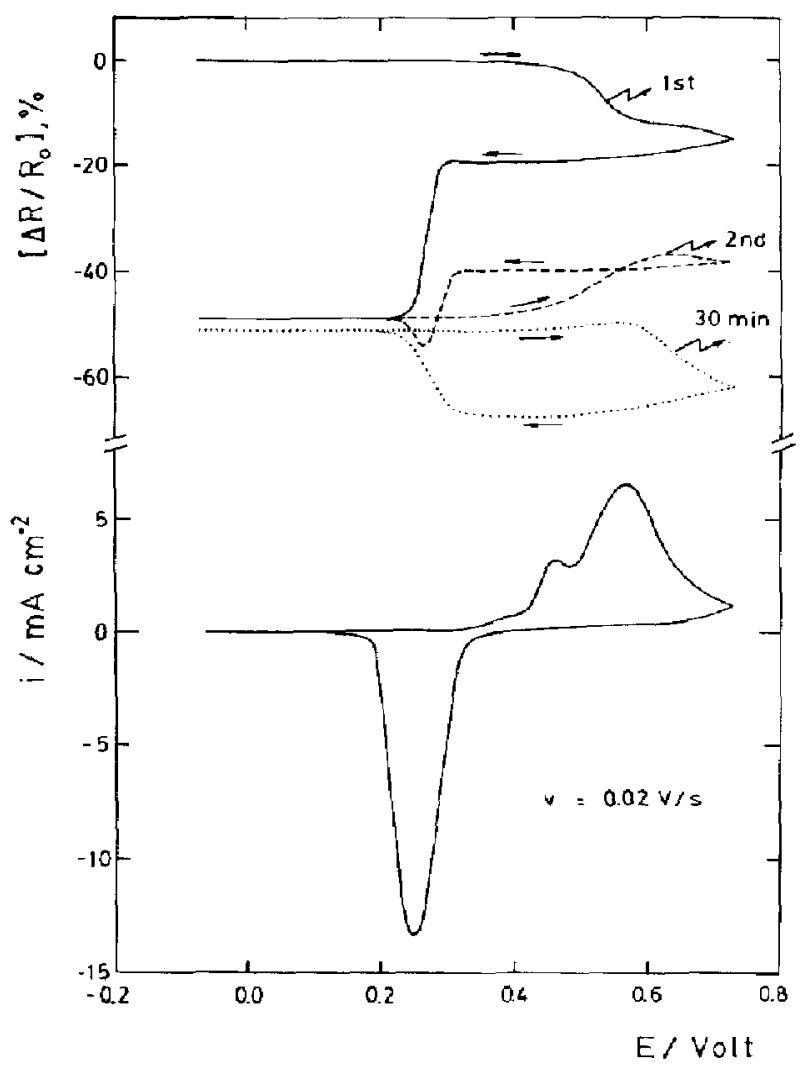

Fig. 9. Reflectivity data resulting during the 1 st and 2 nd triangular potential sweeps at $0.02 \mathrm{Vs}^{-1}$ and after $30 \mathrm{~min}$ RTPS. The corresponding stabilized potentiodynamic $E / i$ plot is also shown to correlate optical and electrochemical responses of the system.

of the reaction as determined potentiodynamically [22]. In this case, two different kinetic laws were derived for thick $\left(Q_{\mathrm{a}}>100 \mathrm{mCcm}^{-2}\right)$ and thin $\left(Q_{\mathrm{a}}\right.$ $<50 \mathrm{mCcm}^{-2}$ ) anodic films, respectively. The qualification of either thin or thick film is given in terms of the charge involved in the corresponding electroformation process. Accordingly, layer I prevails when the anodic film charge is smaller than $20 \mathrm{mC} \mathrm{cm}^{-2}$. On the other hand, layer 11 becomes predominant when the anodic film charge exceeds $50 \mathrm{mC} \mathrm{cm}^{-2}$. It is likely that the degree of hydration of the anodic film is maintained at large potential sweep rate. This would mean that the coupling of the rate of film dehydration, probably through the electronxidation of water, with the electrical perturbation disappears during the fast potential sweeps.

When practically only either layer I exists (limiting case I) or when the charge related to layer II is sufficiently large in comparison to that of layer $I$, the average thickness of the latter is negligible (limiting case II), then the optical properties of the anodic film can be related in principle, to those of a simple single layer. Thus, for a constant wavelength, the corresponding ellipsometric response becomes principally a function of the refractive index, the absorption coefficient and the average optical thickness of the single film. For this purpose theoretical $P$ vs $A$ plots (Fig. 10) were

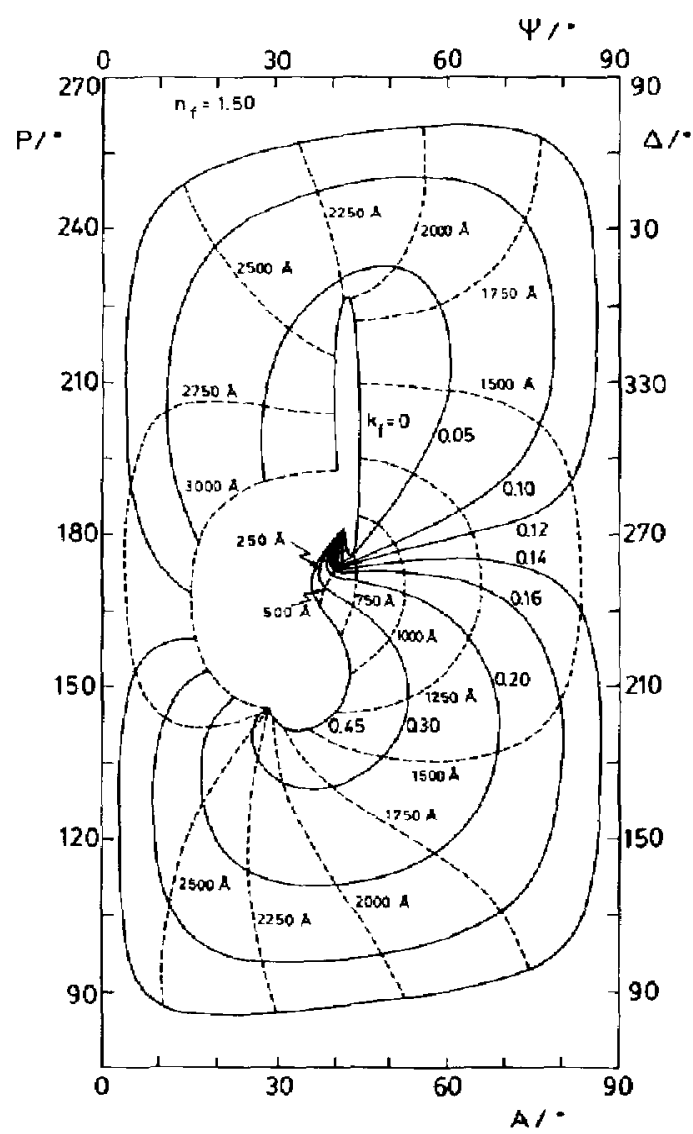

Fig. 10. Theoretical $P$ os $A(\Delta$ os $\Psi)$ plots computed at $n_{f}=1.50$ and different $k_{f}$ and film thickness values, on the basis of a single layer model.

simulated according to the program developed by McCrackin[26], taking for silver the refractive index and absorption coefficient resulting from $P_{0}$ and $A_{0}$, keeping the refractive index of the film constant. $n_{\mathrm{f}}$ was set bet ween 1.40 and 2.17 , the latter figure corresponds to pure $A_{g_{2}} O$ [23]. The variation of $P$ and $A$ with the film thickness (in the $0-3000 \AA$ range), was computed for different values of the absorption coefficient $\left(0 \leqslant k_{\mathrm{f}} \leqslant 0.60\right)$ taking for the refractive index of the solution $n_{0}=1.33$.

The comparison of the theoretical (Fig. 10) and experimental (Fig. 4) $F$ vs $A$ plots shows that a change only in $n_{f}$ cannot explain the remarkable changes in shape of these plots with $v$ and $Q_{\mathrm{a}}$ but for a constant $n_{\mathrm{f}}$, small values of $k_{\mathrm{f}}$ are related to anticlockwise loops in the $P$ vs $A$ plot, while large values of $k_{\mathrm{r}}$ are associated with the reverse loops. From this comparison, it seems reasonable to conclude qualitatively that $k_{\mathrm{f}}$ changes accordingly to $v$ due to the formation of anodic films of different types. From these plots one also observes that even for the same optical thickness two different situations arise depending whether the anodic film is produced at a large or low potential sweep. The best value of $n_{f}$ for fitting the results is however slightly smaller than that used by Müller for interpretating the ellipsometric results of the galvanostatic oxidation of silver in base[23]. On the other hand, the anodic film 
formation process implies an increase in the electrode roughness during the electrochemical reaction. The latter must influence the optical properties of silver as reflected through $P$ and $A$, particularly in the early

alkaline solution obtained through the application of different relaxation techniques[22] and confirm a complex structure for the metal/solution interphase. This structure can be represented by the following scheme:



stages of the anodic process.

From the comparison of theoretical and experimental data (Figs 4 and 10), for thin anodic films $\left(v>0.01 \mathrm{~V} \mathrm{~s}^{-1}\right)$ the complex refractive index equation which reproduces the region of the $P$ us $A$ plot extending between $20 \mathrm{mC} \mathrm{cm}{ }^{-2}$ and $50 \mathrm{mCcm}^{-2}$, within $5-10 \%$ is $\bar{n}_{\mathrm{f}}=1.50-0.12 \mathrm{i}$. Analogously, for thick anodic films $\left(v<0.01 \mathrm{Vs}^{-1}\right)$ the best fitting results for $\overline{\boldsymbol{n}}_{\mathrm{f}}=1.50-0.22 i$. The corresponding values of $k_{\mathrm{f}}$, support the conclusions from electrochemical data[22], namely that the water content of layer $I$ is likely to be greater than that of layer II.

Time effects of the optical parameters correlates with those observed in the electrochemical response of silver in base. The difference in optical behaviour of the anodic film during the potential cycling can be related to the change of the silver roughness and to reactions in the oxide phase which modify the structure of the film, such as those involved in the ageing of anodic films. The time dependence of the optical parameters occurs in the direction one should expect if the average anodic film thickness decreases, that is the values of both $P$ and $A$ approach $P_{\circ}$ and $A_{\circ}$ respectively. The decrease in the average film thickness deduced from electrochemical data can be due either to its chemical dissolution through the formation of anionic silver as suggested by Droog et al.[19], or it can be related to reaccommodation of the anodic film whose density increases as the water content of the film changes during time. The former explanation is consistent with the fact that under certain potential perturbation conditions $Q_{\mathrm{a}} / Q_{\mathrm{c}}>1$. As a matter of fact, the anodized electrode kept under open circuit for a certain time shows a decrease of the electroreduction charge. The solubility of the anodic film is more remarkable for thin films, as it results for anodic films made by single potential sweeps up to different $E_{\mathrm{s}, \mathrm{a}}$. Acuording to the structure assigned to the anodic film its solubility is apparently directly related to its degree of hydration.

The optical properties of the reformed silver resulting after anodizing are very different of those of polished polycrystalline silver. This can be associated with the dynamic characteristics of freshly reformed silver and with the considerable enhancement of the electrochemical activity of silver as it occurs when these electrodes are subjected to prolonged electrooxidation and electroreduction cycles by means of different potential perturbation programs[24]. The ellipsometric parameters of reformed silver apparently correlates also with the enhancement of Raman spectra of various compounds on silver electrodes [27-29]. These effects, which were also reported for gold $[30,31]$ and copper [32] electrodes in diflerent electrolytes after perturbing with similar potential programs, have been associated with the electrodeposition of small metal globuli of a few hundred nm average diameter[29].

The present results are coherent with those recently reported for the electrochemical response of silver in
The formation of $\mathrm{Ag}(\mathrm{OH})_{\mathrm{ad}}$ in the order of a monolayer thickness $\left(d_{\mathrm{o}}\right)$ at the early stages of silver electrooxidation in base was concluded from the reversible fine structure of triangularly modulated triangular potential sweeps $E / i$ profiles[33]. Layer I is assigned to the $\mathrm{Ag}(\mathrm{I})$ oxide inner hydrated and layer II is associated with the $\mathrm{Ag}(\mathrm{I})$ oxide outer layer. For thin anodic films the thickness of the former $\left(d_{1}\right)$ is apparently much larger than that of the latter, while for thick anodic films $\left(d_{1 \mathrm{I}} \gg d_{\mathrm{I}}\right)$ the reverse situation is approached.

One may argue that layers I and II be related to $\mathrm{Ag}(\mathrm{I})$ oxide and Ag(II) oxide species, respectively, as reported from the Raman spectroscopy study of different silver oxides on silver in $0.1 \mathrm{M} \mathrm{NaOH}$ [34]. The absence of electroreduction of $\mathrm{Ag}$ (II) species in the potentiodynamic response of the anodic layers in the range of charge covered by the present experiments [22] discards, in principle, that the major constituent of layer $\mathrm{II}$ is $\mathrm{Ag}(\mathbf{I I})$ oxide. Therefore, as previously suggested by Ross and Roberts[35], the contribution of the light from the ellipsometer to form Ag(II) species is probably small.

Acknowledgements-INIFTA is sponsored by the Consejo Nacional de Investigaciones Científicas y Técnicas, the Universidad Nacional de La Plata and the Comisión de Investigaciones Cientificas (Provincia de Buenos Aires). M.L.T. participates in this work under a leave of absence from the Universidad Nacional de Córdoba supported by a grant from the Consejo de Rectores de Universidades Nacionales of Argentina. The authors akso thank Prof. Dr. J. M. Vara Cuadrado for the critical revision of the computation program.

\section{REFER ENCES}

1. L. Young, Anodic Oxide Films, p. 302. Academic Press, London (1961).

2. J. P. Hoare, The Electrochemistry of Oxygen, p. 211. Interscience, New York (1968).

3. N. A. Shumilova and G. V. Zhutueva, Encyclopedia of Electrochemistry of the Elements (Edited by A. J. Bard), Vol. VIII, p. 1. Marcel Dekker, New York (1978).

4. G. T. Croft, J. electrochem. Soc. 106, 278 (1959).

5. R. Glicksman and C. K. Morehouse, J. electrochem. Soc. 104, 599 (1957).

6. S. A. Rozentsveig, B. V. Ershler, E. L. Shtrum and M. M. Ostanina, Akad. Nauk. SSSR Otdel. Khim. Nauk. 1950, 571 (1953).

7. Z. Takehara, Y. Namba and S. Yoshizawa, Electrochim. Acta 13, 1395 (1968).

8. P. Stonehart, Electroctim. Acta 13, 1789 (1968).

9. G. T. Burstein and R. C. Newman, Electrochim Acta 25, 1009 (1980).

10. R. D. Giles, J. A. Harrison and H. R. Thirsk, $J$. electroanal. Chem. 22, 375 (1969).

11. J. Ambrose and R. G. Barradas, Electrochim. Acta 19, 781 (1974).

12. B. V. Tilak, R. S. Perkins, H. A. Kozlowska and B. E. Conway, Electrachim. Acta 17, 1447 (1972). 
13. R. S. Perkins, B. V. Tilak, B. E. Conway and H. A. Kozlowska, Electrochim. Acta 17, 1471 (1972).

14. J. M. M. Droog and T. Huisman, J. electroanal. Chem. 115, 211 (1980).

15. D. B. Gibbs, B. Rao, R. A. Griffin and M. T. Dignam, $J$. electrochem. Soc. 122, 1167 (1975).

16. B. Miller, J. electrachem. Soc. 117, 491 (1970).

17. E. B. Brick, R. M. Lazorenko-Manevich and Ya. M. Kolotyrkin, Electrokhimiya 13, 1520 (1977).

18. Z. I. Kudryavtseva, V. A. Openkin, N. A. Zhuchkova and N. A. Shumilova, Elektrokhimiva 14, 517 (1978).

19. J. M. M. Droog, P. T. Alderliesten and G. A. Bootsma, $J$. electroanal. Chem. 99, 173 (1979).

20. J. M. M. Droog. J. electroanal. Chem. 115, 225 (1980).

21. M. López Teijelo, J. R. Vilche and A. J. Arvia, J. electroanal. Chem. 131, 331 (1982).

22. M. López Teijelo, J. R. Vilche and A. J. Arvia, $J$. electroanal. Chem. in press.

23. R. H. Müller and C. G. Smith, Surf. Sci. 96, 375 (1980).

24. G. I. Lacconi, A. S. Gioda and V. A. Macagno, in preparation.
25. C. A. Fenstermaker and F. L. McCrackin, Surf. Sci. 16, 85 (1969).

26. F. L. McCrackin, Nat. Bur. Stand. Tech. Note 479, U.S. Govt. Printing Office, Washington (1969).

27. A. Otto, J. Timper, J. Billmann, G. Kovacs and I. Pockrand, Surf. Sci. 92, L55 (1980).

28. J. Billmann, G. Kovacs and A. Otto, Surf. Sci. 92, 153 (1980).

29. C. C. Busby and J. A. Creighton, J. electroanal. Chem. 133, 183 (1982).

30. R. Córdova O., M. E. Martins and A. J. Arvia, J. electrochem. Soc. 126, 1172 (1979).

31. M. E. Martins, R. Córdova $O$. and A. J. Arvia, Electrochim. Acta 26, 1547 (1981).

32. M. E. Martins and A. J. Arvia, J. electroanal. Chem. in press.

33. J. R. Vilche and A. J. Arvia, Corros. Sci. in press.

34. R. Kötz and E. Yeager. J. electroanal. Chem. 111, 105 (1980).

35. D. Ross and E. F. I. Roberts, Electrochim. Acta 21, 371 (1976). 